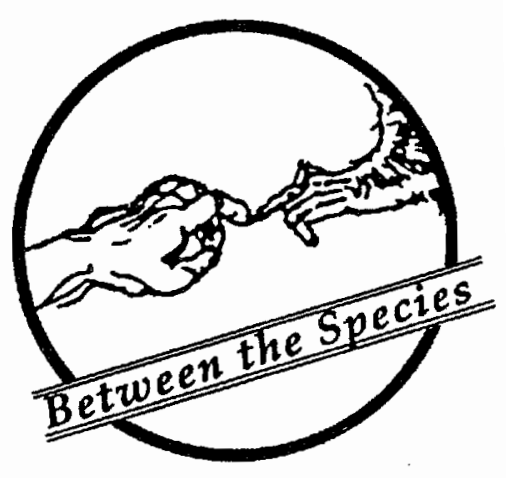

\title{
The Death of the Animal: Ontological Vulnerability
}

Kenneth Joel Shapiro

Psychologists for the Ethical Treatment of Animals

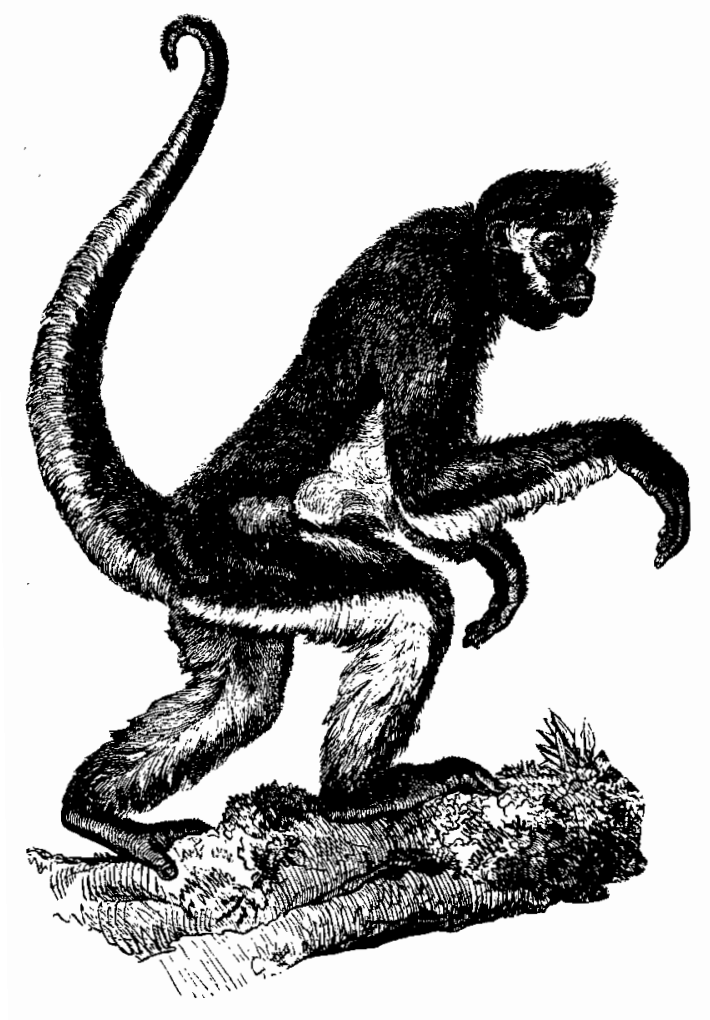

\section{Introduction and Theses}

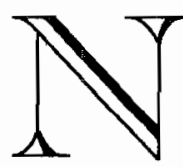

onhuman animals are vulnerable to all manner of plights and plundering at the hands both of nature and of human institutions and practices, from predation, natural disaster, and disease to trapping, veal-calf crating, and electric shock. In this paper we explore a certain class of such plights and plundering and those features of animals that leave them peculiarly vulnerable to them. In the spirit of Heidegger's distinction between the ontic and ontological, ${ }^{1}$ we will call these an animal's "ontological vulnerability." 
The term will be clarified further through the presentation. For the moment, an example from my own field of phenomenological psychology provides an initial handle. In his early work on schizophrenic and schizoid ways of being, R.D. Laing (1965) describes a type of person who lives as if he or she is not a self but is a thing. He or she is not just an inadequate or a bad self, but is a no-self. Such a being does not live as a center of autonomous action. As distinguished from the loss of a particular self, this loss implies an ontological vulnerability in that there is, at least apparently, a loss of the structure that makes it possible for a person to become any particular self. ${ }^{2}$

We will describe two types of such vulnerability in nonhuman animals. The first is a vulnerability to the loss of individuality. Again, the threatened loss here is not merely the failure to achieve a particular style or feature, or personal or social history that might constitute an animal as an individual, but is the ontological threat of loss of the possibility of being an individual. We will link this death of the individual to a humanistic concept which categorically excludes nonhuman animals from the status of individual. Finally, we will suggest that certain features of animals, such as limitations in reflective and linguistic capacities, invite this reductive social construction of animality.

The second type of ontological vulnerability is a loss of species identification wherein an animal becomes what we will call a "generic animal" or an organism. This reduction is exemplified through an account of laboratory research using animals. It will argued that this vulnerability is made possible through a radical dependence in the case of nonhuman animals on their species specific habitat, by contrast to the human possibility of a relative transformation, through symbolism, of his or her setting. By contrast to the first type, we will show that this second reduction, more clearly, actually occurs. Beyond the social construction of the generic animal, we actually create such beings.

In that my approach here is that of a phenomenologically oriented social scientist, for both types I will first describe certain contemporary ways of living toward nonhuman animals which both build on and help sustain the two ontological reductions. This approach is akin to but distinguishable from an analysis using label and social role assignment (Herzog, 1988). It is more directly a derivative of the social phenomenological approach of Schutz in which reality is described as a social construction consisting of networks of typifications (Berger and Luckmann, 1966). However, in addition to describing relevant ways of living toward a particular object, in regard to the second reduction, I will also attempt a more direct explication of that object's, an animal's, way of being, again employing phenomenological method."

The term "death of the animal" is an allusion to Barthes' "death of the author" (1977). In that seminal postmodernist essay, Barthes crystallizes the sense in which certain intellectual trends are changing the way we live toward authorship. For example, in this attitude a text is less the creative fulfillment of an individual artistic intention than it is a conduit for prevalent images and ideas in various language communities. The author has died in the sense that we, including the author, no longer live toward what he or she is doing in "creating" a text as authorship, in the traditional meaning of autonomous creative agent. By "death of the animal" I refer both to our living toward animals as a reduced kind of being and to practices that actually effect an ontological reduction in animals.

\section{Deindividuation: An Animal As Species}

Although subtle and complex in their origins and maintenance, the ways we refuse to live toward an animal as an individual are familiar and pervasive. When $I$ argue with a deer hunter or my neighbor who now permits trapping his land where my dog used to run, or the local game warden, we usually talk past each other. We do so not simply because we disagree (I can talk to Republicans), but because I tend to refer to that deer as that individual, the one the hunter wounded and then, after tracing the buck in the field across the way, killed; while he or she refers to "the deer," as for example, the status of the deer species in Maine this fall following a particularly mild winter and early spring. "The deer" refers to a species as a reified entity rather than 
as an aggregate of individual deer. General academic consensus notwithstanding (Munson, 1971), for him or her a species is not an abstraction. Correlatively, that deer he or she just killed is not (or was not) a concretely present individual, for any one deer is largely lived toward as a part of that reification, "the deer."

Our difference is not just talk. We live toward and act in regard to that deer accordingly. The distinction is a fundamental one at the level of the structure of our respective experiences. In phenomenological terms, Husserl makes a strong distinction between an act in which we mean an object as an individual and one in which our object is an instance of some specific feature (in Farber, p. 246). In the former case, we "simply mean the appearing thing itself" (that deer right there), while in the latter we refer to some specific feature or features of that deer, some idea or content of deerness. In the latter case, the specific feature is focal (here a feature or features that identify a particular species), while the individual, that deer there, is backdrop. More radically, the existing and present individual is forgotten or nonexistent while the abstract and absent species is all there is.

Ironically, while at least apparently, it is the hunter who is "being there" with that individual deer (I once got within fifty yards of a deer), while it is the hunter who lets that buck live or suffer and die, who touches him and his lifeblood at the moment of his death, that deer is not there for him or her. What is there is an impersonalized, deindividualized but reified abstraction, as, for example, some feature of the population of the deer herd in Maine. In the same move, this reification of the species dissolves the individual deer and invests the aggregate of, now, non-individuals with a kind of unified being that allows members of the species to be killed as if they were so much grass being mowed. In Heidegger's term, this deer is lived toward as a "standing reserve," a resource there waiting for our use (1977).

While readily apparent in wildlife management practices, deindividuation is not limited to that context. Down on the factory farm, individual animals are long gone. Factory or intensive farming began to accelerate in devel- opment during the years around World War II (Mason \& Singer, 1980). There the tension is between the two poles of our second ontological reduction - from species to generic animal. "Beef," "pork," and "chicken" are vestiges of species-specific consideration. "Meat" is already a reference to the generic animal. (Of course, a further reduction, not dealt with in this paper, is from generic animal to commodity, from meat to price of meat, from animal to stock.)

But even the companion animal, among whom is "man's best friend," is vulnerable to deindividuation. Our consciousness of breed often supplants our awareness of even our own pet's individuality. Temperament, peculiarities, personality are lived toward as species-specific rather than as idiosyncratic, as a feature of this individual. When my dog dies, friends suggest that I go out and replace him - you'll feel better, they say with best intentions. That I lived with that dog for eight years, that I saw him through the death of his adoptive mother and the trapping incident and that he saw me through comparable events in my life is of no count. Their reference is not to that particular, historical intimate relation, to the world we had together; rather, implicitly they refer to black labs and how they make gentle companions. This attitude allows the practice of abandonment in shelters and "sacrifice" in labs of our nonhuman animal companions.

A version of a utilitarian ethic, what Singer calls the total view (1979, p. 100) embodies a derivative form of deindividuation. In this view, a being is merely a receptacle of something valuable. That valuable something can be as easily contained in another receptacle. Hence, the replacement of one with another has no ethical cost. In more phenomenological terms, Laing and Cooper, explicating Sartre, describe a relation of seriality in which one individual lives toward a second in a relation of externality and interchangeability (1971). In their example (pp. 121-2), the person in front of me when I am waiting for a bus is reduced to a member of a collectivity. Being only one of so many in line, he or she is identical with and replaceable by any other member of the group. This serial identity and consequent replaceability is in turn made pos- 
sible by the fact that each entity is lived toward as a receptacle of certain features common to the group. Each entity in the line is only a placetaker as each black lab is only a container of certain features of that species. So, I can go out and replace him.

One way to understand how we come to deindividuate nonhuman animals so pervasively and, typically, so thoughtlessly involves a review of the history of "individual" as a social construction. As I have argued more fully elsewhere (Shapiro, in press, a.), one still dominant social construction of individuality took nonhuman animals as the categorical foil. In this construction animals are defined as the exemplar non-individual in order to more discretely and exclusively preserve individuality for human animals. A humanistic philosophy defined rationality or reason as that feature which is both free and freeing. It argued that free reason is the sine qua non of individuality, for only an individual is self-determining or autonomous. Precisely in distinction from humans, nonhuman animals are instinct and need-dominated rather than rational. Despite its etymological origin in spirit or mind (L. animus) and in quickening or moving autonomously (L. animare), in this construction "animal" refers to the instinctoid, the biologically determined, the nonrational. Given the gulf between nonhuman and human animals created by this ideology, humanistic philosophy can then justify its reinforcement by the epistemology that we can only know animals through a scientific method in which reason is applied to objective and distanced observation of these now strangely "other" creatures. In the correlative political-legal system, only individuals are granted legal rights. Hence, as nonindividuals, animals have no rights and no legal standing. By sanctioning our forgetting the individuality of nonhuman animals, these philosophies and traditions support our living toward them as certain reified classifications, as species.

In a general way, certain features of animals permit this discriminatory "modernist," as we now call it, conception of the individual. Some animals are not rational; others are apparently not; none are by traditional humanistic lights. Certainly, animals do not appear to be rational to a viewer for whom language is a prerequisite for, if not coterminous with, rationality. The attempts of nonhuman animals at communication generally seem limited to structures that are less sophisticated than those definitive of language, again, at least by humanistic lights. Neither do animals assert their individual rights nor, for that matter, make any claims. They do not refer to their grievances for their capacity for self-reference is very limited. ${ }^{4}$ Further, their behavior does appear to be largely intelligible in terms of its typicality for a given species. Both personal identity and individuality seem much less prominent than this species-specific behavior. Surely, one could apply the quip, attributed to a now obscure political figure, "if you've seen one redwood, you've seen them all," with almost as much conviction to a gazelle or a sea lion. In all of these features, the traditional humanistic view of nonhuman found easy purchase.

Of course, the modernist conception of individuality is under attack from many quarters of what is loosely referred to as postmodern thought, all of which agree that individuality, along with "man" himself, is a social construction, a product, in Foucault's term, of a particular episteme (1973, p. xxii.). Postmodern thought brings human being down from its romanticized humanistic heights. For example, we have already alluded to the displacement of authorship, from the author as the seat of unique, creative intentions, to an emphasis on language and language communities that, as it were, speak for themselves and in the service of which individual authors are mere conduits. An "individual" is derivative of language both in the sense that individuality itself is a historically evolving socio-linguistic construction and in that the provenance of what I way, including the story I tell to define myself as an individual, is traceable to a second-hand loaner from the current culture. Utilizing the metaphor of height so often applied, (although mistakenly [Midgley, 1978, pp. 158160]), to the traditional human-animal distinction - if human is a "lower animal" relative to language, then, we humans are now closer, in the postmodern construction of subject and individuality, to the other lower animals. Language (and with it rationality) is no longer the critical cleaver between human and animal precisely because it is no longer between them, being now conceived as 
above or as the primary surround or medium within which human experience can be meaningful.

Several other developments complement bringing human being down by raising animal and, in some instances, inanimate being up. Stone (1974) claims legal standing for trees, although he has recently retracted or softened his original claim (Varner, 1987). Following Whitehead, Hartshorne's process philosophy argues a concept of individuality so broad as to include plants, and, at least in the most primitive of several degrees or forms of individuality, each cell within a plant (Dombrowski, 1988). Far from premised on an exclusionary notion of reason, here individuality is "based on a pattern of interaction" (p.4) and participation in an event or process. In a stronger sense of individuality, animals are true individuals in that they are wholes that both participate in and experience these events. A final example is, of course, Regan's philosophy of animal rights which confers the rights of an individual to nonhuman animals (at least mammals of more than one year of age) on the basis of their being "subjects of a life" (1983).

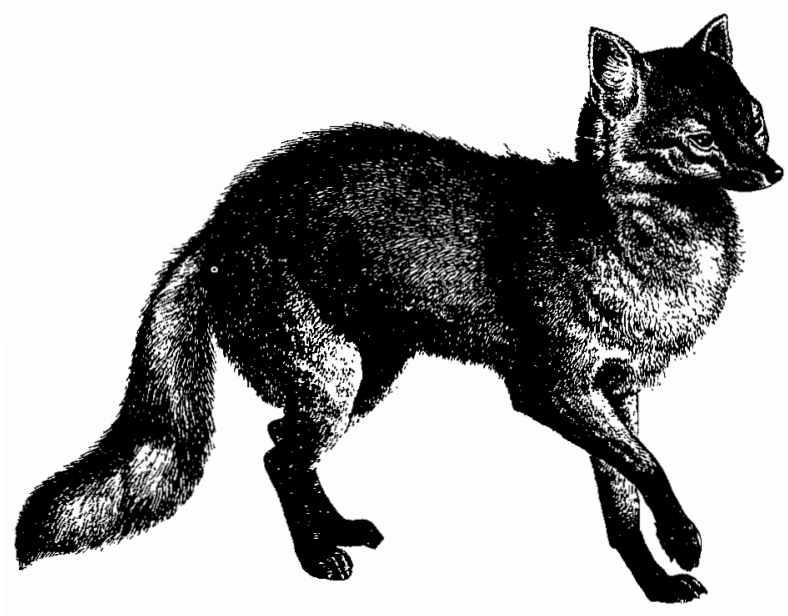

In addition to deconstructing modernist claims as to the truth about human being in general and individuality in particular, postmodernism offers its own more relativistic and self-consciously reconstructed views of individuality. One such view emphasizes historical context and embeddedness and, particularly, narrative accounts of a person's history as the stuff of individuality (Ricoeur, 1984). "People conceive of themselves in terms of stories" (Polkinghorne, 1988, p. 107); individual identity consists in a person's narrative account or story of his or her life.

At first glance it would appear that animals are as vulnerable to deindividuation in such a reconstruction of individuality and individual identity as in the earlier modernist conception, for they are not historians or story-tellers. However, as I have argued elsewhere (Shapiro, in press, b.), history informs the experience of a particular animal whether or not it can tell that history. Events in the life of an animal shape and even constitute him or her. To understand my dog Sabaka, I need to know his history, how he was abandoned at the dump as a pup, how he was "raised" by another dog we adopted at roughly the same time as Sabaka and how that dog died a year later. For, clearly, these vents inform Sabaka's behavior, his personality, and partly constitute his individuality. Sabaka is an individual in that he is not constituted through and I do not live toward him as a species-specific behavioral repertoire or developmental sequence. More positively, he is an individual in that he is both subject to and subject of "true historical particulars" (Gould, 1987). I can not replace him, nor, ethically, can I "sacrifice" him for he is a unique individual being.

\section{Generic Animality}

To recapitulate to this point, in the first part we argued (1) that we can and do live toward an animal forgetting his or her individuality, and (2) that a certain vulnerability in nonhuman animals allows the social construction which in turn supports that attitude.

In this section we will argue that a second reduction is possible and indeed prevalent. We can and do live toward an animal in a way that 
denies it its species identity as well as its individuality. (" $\mathrm{It}$ " seems the more appropriate pronoun as we move from the individual/species to the species/generic animal interface.) Here, however, we will argue further that this social construction and a certain vulnerability in animal being combine to effect the actual reduction - an animal is reduced to a generic being. This reduction is ontological rather than ontic in that an animal loses not just a particular species identity but the possibility of being any species. Since the argument for the actual loss of species being is more problematic, we will begin with a description of the social construction of a generic animal.

We will argue that this second reduction is more prominent in our practices toward laboratory and factory farm animals, while the first reduction more often prevails as our attitude toward wild and companion animals. However, the following introductory example features a wild animal for I find the attitude more intuitively compelling and more popularly accessible in that context.

A lion in a cage is not a lion. Of course, as we stand at the cage in which this animal is exhibited, we can imaginatively place it in the African savannah, lying near a thicket, having shared its kill with its pride and now licking its paws and enjoying its repose with a giant yawn. But even an individual of this most familiar species, mythologized as the king of beasts, we as often experience in terms of the stereotypic behavior of any large mammal permanently housed in a small cage. The repetitive pacing and rocking, the lack of interaction with and interest in conspecifics and surroundings fail to evoke lion country. When our experience takes this turn, we are beginning to live toward this animal as a generic being, as neither a locus of individual nor of species-specific being.

In the less familiar setting of modern intensive animal husbandry, this attitude is almost unavoidable. Consider that a chicken, for example, shares with three or four other chickens a cage the floor of which is little larger than this journal page, and that the structure housing the cage contains as many as 80,000 chickens (Mason and Singer, 1980). For the factory farm worker, the chickens are, focally, a job to be done. They are only animals implicitly, occasionally, and, undoubtedly, reluctantly. As animals they are lived toward as potential meat or eggs, produce, or producers of stock for the market.

In the research laboratory, animals are also caged. In this setting they are primarily lived toward as objects of study. ${ }^{5}$ Typically, in both biomedical and psychological research, the object of study is a general process rather than a speciesspecific physiology or behavior. The animal is lived toward as a "preparation" (Devereux, 1967) where what is being readied is not a rat or cat or dog but an organic or behavioral process. Whether through stereotaxic fixation or anesthetization or restraint in a Pavlovian sling, the preparation or making ready is an attempt to eliminate any individual and species identity in order to disclose for study a general process, a biological organism, a generic animal. ${ }^{6}$

The term "generic" has recently become laden with meanings and we must pause to unpack it. In the supermarket and in the drug store, generic brands refer to products that offer the genuine article with relatively little packaging, and, in some instances, with minimal adulteration and "refinement." Peanut butter becomes nothing but peanuts buttered, no longer contaminated by dextrose, partially hydrogenated vegetable oil, salt and corn sweeteners. By contrast, in the context of literary works, generic refers to a reduction to a minimal form that delivers a sensationalized, merely titillating derivative without the genuine article. On the side of the "author," a harlequin romance is a produce made and assembled by a formula. On the side of the reader, it is "love" without a relationship, sensuality without the body, only packaging.

We read these related cultural trends to express an ambivalence between the modernist searches for a universal essence and for a transparent self-consciousness. As Lasch has described (1979), in recent times the latter has degenerated into a narcissism in which the self dissolves and is sought in externally provided mirrors. An object is generic, then, when its pure essence is sought or when merely the effect on self of that essence is sought. In this paper, our use of the term refers to a possible effect in the 
object of such ambivalent and confused quests namely, the loss of both individual particularity and species typicality.

Since it is common to all of the three examples, zoo, factory farm, and laboratory, we will take "cage" as a metaphor for the reduction to generic animal. While not a necessary concomitant, we will use "caging an animal" to refer to a way we can live toward an animal kept in a radically depleted setting. That divorce from a fuller, more "enriched," usually more naturalistic setting may be in the service of market quality, as in intensive farming, or of control, as in laboratory research. In the latter, experimental control typically is the attempt to eliminate all variability attributable to individual and species-specific behavior. Through this regulative ideal, this natural scientific enterprise believes a general or essential nature can be revealed.

When we live toward the lion (or chicken or rat) as a caged animal, we have lost both lion country and lion behavior, both species-specific habitat and behavior or habit. What, if anything, is the comparable loss for the animal? We turn now to a consideration of the life of an animal lived toward as generic. Beyond our social constructions of an animal in a cage, we will have to show that a particular setting is a precondition for a particular species being. Absent that precondition, we can then assess whether the resultant generic animal is a destructive trivialization or a revelation of the universal; and, finally, whether that reduction is harmful to an animal.

The form of nonhuman animal being is ambiguous in that it derives from both individuality and species membership. The relative power of the two determinants underlying both (respectively, although only roughly, individual history and biological givens) varies in the different animal life-forms. We are concerned in this section with the contribution of species membership to an animal's being, with the possibility of the loss of that contribution, and with understanding what is left following that loss. Analogous to the folk-ways that an anthropologist locates in a given culture, we will refer to the behavioral forms peculiar to and typical of a given species as "species-ways."
The concept of species must be clarified. For Aristotle, each kind of animal has a telos, an unchanging nature that distinguishes it and that is the "sole determinant of its form" (Bakan, 1971, p. 341). By contrast, with Darwin telos or species can change gradually, not for a given animal but from individual to individual over time. In contemporary evolutionary theory, there is also the possibility of relatively dramatic and discontinuous change in a species or in the emergence of new species (Gould, 1982, pp. 179-186). In both these versions of evolutionary theory, although species and species-ways can now come and go, they do so under nature's auspices.

However, beyond this loosening of the classical notion of telos in evolutionary theory, with the advent of behaviorism and genetic engineering the concept becomes unrecognizable. In the most radical version of behaviorist theory, there is no consideration of ways typical of and determined by species identity. Environmental contingencies determine animal (and human) behavior. An animal has no intrinsic nature, species-specific or otherwise, beyond its "capacity" to be passively determined by its environment. While the environment can not quite effect flight in mice (they can be "taught" to leap off a platform), it can "shape" ping-pong playing and a preference for pictures of people, in pigeons. At least in accord with this theory, the radical behaviorist already lives toward an animal as a generic being. While radical behaviorism is in decline, methodological behaviorism is still dominant and, arguably, evokes this attitude in the investigator.

With the development of genetic engineering, both the classical and Darwinian concept of species are challenged again. With technology that allows material from different species to be spliced together, animals are produced which stretch any notion of the hybridization associated with selective breeding. The genetic engineer thinks less in terms of combining discrete species-ways and more in terms of gene pools that consist of raw material or raw information. The genetic code peculiar to a given animal has no more intrinsic integrity than one filing system among many. A species is a momentary organization of a certain chunk of information. An individual animal is reduced to certain genetic 
information that can be readily otherwise informed. The form and species-way of an individual animal are reduced to the expression of certain genetic information - form follows information. The way of living toward an animal consistent with the concept of genetic material or manipulable information is, by our definition of the term, as generic being.

\section{T he spider's web \\ I notwithstanding,}

human beings are the

consummate cage-makers.

Only we can exhibit an animal.

Here we will locate a concept of species and species-ways that is mid-way between the Aristotelian concept of a fixed and intrinsic nature and these contemporary denials of a species-specific nature. Ecology directs us foremost to an ecosystem and to the relations that comprise that system. In ecology species refers to a typical morphology and behavior and its relation to a certain environment. But environment (etymologically from $\mathrm{F}$. virer, to turn; by extension meaning circuit or surround) does not capture the constitutive role of that relation in animal being. An animal is not merely surrounded by, so much as it is a constituent part of that system. Species-ways are part of what effects a certain ecosystem. In the other direction, the effect of ecosystem on species-ways is as constitutive and is better captured by the terms "habit" and "habitat" (L. habere, to have and hold) than by the term environment. When we say that the animal inhabits a certain habitat we mean that a particular habitat is the necessary locus of being of a particular species. The dynamic relation between lion and lion country is constitutive of lion being. That part of animal being that is attributable to species membership is radically dependent on natural habitat for more than merely a surround or medium, it is necessary for the animal to be that species. The animals of a particular species dwell there in the sense that they have their being there. Lyons (1989, personal communication) writes that "the flower is part of the bee's anatomy." This is true in the sense that habitat and habit are a unity necessary for the possibility of that insect-way.

By comparison a human being is its habitat in a weaker sense. Through reflection he or she can take up a posture to a given environment and, thereby, can transform it symbolically to create with it a world. Unable to construct a world by taking a reflective posture to selected features of its environment, a nonhuman animal becomes itself only through certain features of that habitat. A nonhuman animal's radical dependence on a species specific habitat is part of its ontological vulnerability to the reduction to generic animal. By contrast, through his or her power of symbolic transformation a human being in a cage or prison is limited to ontic suffering. He or she remains a being burdened with the ability to make the meaning of that experience explicit. ${ }^{7}$ However, the loss of a lion deprived of lion country or of a bee without flowers is ontological as well as ontic.

In another work (Shapiro, in press, b.), I describe how my dog seeks and establishes possible habitations, places that he appropriates as his own and which serve as vantage points or points of view for him. An animal's habitat is his or her dwelling place not only in the sense of providing a particular home but in the sense of being the substance of his or her species identification. A species way or habit requires inhabiting a certain habitat. Niche is constitutive, not substitutive. The notion that an animal's telos remains inside, intact and unchanging as long as its biological integrity is maintained is a limited and convenient abstraction. To "ex-hibit" an animal in a cage is to take it out of its habitat which is to lose its species-way which is to reduce it to a generic animal.

As we indicated we have taken "caging" as a metaphor for the possibility of the reduction to 
generic animal. Obviously, not all caging of all animals has that effect. Now we must say when that reduction actually does occur. We anticipate several major problems. Is not what a rat does whether in a field, apartment building, or cage - rat behavior? Is not the way an animal adjusts to whatever manipulation of environment to which it is exposed its typical species-way? If many species adjust in a similar way or with similar behavior to radical manipulation or depletion of setting, is not that still a species-way, although common across species? If a species is selectively bred or genetically engineered to behave in a certain way in a depleted environment, is not that behavior now its speciesway? How can we locate the generic animal in all of this?

Clearly human intervention produces massive change in animals on an individual and species level. Interventions on the species level occur through manipulation of habitat or genetic constitution. Whether in the service of preserving endangered species through habitat management or artificial propagation strategies, or of increasing the population of "game" animals by habitat manipulation, or of increasing the compatibility of companion animals through selective breeding, many of these changes involve either or both external and internal telos manipulation without yet producing a generic animal. Whatever the ecological and social effects and ethics of our having a sandhill crane raise whooping crane babies, or our producing deer in abundance by exterminating their natural predators, or our breeding less aggressive black labs or more efficient sheep dogs, their species integrity is not in question. But consider crating a veal calf or selectively breeding a mouse so that it is susceptible to audiogenic seizures. Intuitively, these are more extreme examples of, respectively, external and internal telos manipulation. Perhaps they are extreme in the sense that the manipulation is more grossly in the service of human need rather than extensions of the particular species defining features. What it tastes like is not directly a part of a cow's species-way, although it is partly a product of what it eats or is allowed or forced to eat. Still, is not a calf who is not allowed to turn around or to see daylight still a calf, and an obese or hairless or tumerogenic rat who cannot gnaw or scurry or explore still a rat, however pathetic?

I suggest that we actually have produced a generic animal when that animal is chronically bored. When the relation between environment and animal is chronically such that the animal has no interest in its environment, the habitathabit unity that sustains and constitutes a speciesway has been split asunder and the lion or chicken or rat is no longer.

Wemelsfelder (1984) offers various indices for determining the presence of boredom in an animal, such as stereotypic movement, redirected activity, vacuum behavior, and immobility over long periods (p. 133). Approaching the present thesis, she further characterizes boredom as a state in which an animal "misses the opportunity to perform its specific behavior" (p. 117), or "does not have the chance to perform the behavior which is part of a species-specific range of behavioral possibilities" (p. 124).

This criterion, the presence or absence of chronic boredom, offers a solution to the problem of when or whether an animal selectively bred or genetically engineered to adjust to being caged is a generic animal. By the way, the result of such practices is apparently not as effective as one might think. After hundreds of generations of life in captivity even the albino rat retains, at least potentially, certain species specific behaviors such as burrowing (Wemelsfelder, pp. 126-7); and after thousands of years of domestication the domestic dog retains vestigial instinctive behaviors associated with its genetic wild forebears (Fox, 1978). However, to whatever degree that we can or could genetically engineer an animal to adjust to being caged, we are arguing that if the animal is chronically bored it has been ontologically reduced to a generic animal. Whether it "misses an opportunity" for species-specific behavior that is genetically "present" or whether it no longer has that genetic potential, if the animal is chronically bored it is living without a species-way.

When this criterion is fulfilled, "adjusting" an animal through genetic manipulation to a radically deprived environment does not produce a new species-way. If the resultant animal is chroni- 
cally bored, "cage-country" and "cage-animal" behavior are not a new habitat-habit unity for there is no dynamic or living relation between them. Finally, while the stereotyped behavior that is pathognomic of boredom is common across species, it is precisely not species behavior both because it is not distinctive or specific and because it is not a way of inhabiting, of dynamically living in and being through a particular habitat. A chronically bored animal is an ex-hibited animal which is, then, a generic animal. While neither all caging nor all genetic engineering results in such, these are the primary means of producing this reduction. The spider's web notwithstanding, human beings are the consummate cage-makers. Only we can exhibit an animal.

While to this point we have restricted our language to the more neutral "reduction" or "loss," we now are in a position to consider whether this second ontological reduction is harmful. In what sense is the actual loss of species-way harmful?

Beginning with Singer's seminal work (1975), the history of the contemporary animal rights movement can be told in terms of a broadening of the concept of suffering in animals. This progression is most clear in the context of laboratory animal research and attempts at its regulation. Initially, the literature on housing of lab animals dealt only with the provision of a minimal standard of comfort for an animal, while experimentation protocols addressed only the minimization of physical pain where possible within the demands of the study. However, these restricted notions of minimal creature comfort and of physical pain are slowly (and resistantly) expanding to include the subjective experience of distress, stress, anxiety and ill-being, and, even absent felt-experience, to include loss of function, deprivation of physical, social and intellective stimulation, and death.

I want to argue here that the ontological reduction to generic animal is a distinct form of harm that yet further broadens the scope of suffering that we visit on an animal.

Consider a caged animal that through some combination of selective breeding or genetic engineering and habitat restriction is chronically bored. In what sense is this animal being harmed? Boredom itself is arguably harmful.
Wemelsfelder characterizes it as a form of distress (p. 137). She speculates that this distress may be related to helplessness, itself a form of stress, or to understimulation. However, in addition to this subjective state, intuitively, the loss of species-way is itself harmful.

To be clear, our focus here is not the more typical concern with the harm done through species extinction induced through human intervention. Arguments proffered to account for the harm consequent upon the loss of a species-way through extinction are difficult enough to make. Often, such ethics are baldly speciesist, locating the harm exclusively in concern for human welfare. For example, Wilson describes a conservation ethic (1984, pp. 119-40) in which "each of the millions of species can be visualized as a book in a library." The survival of a species provides greater diversity of genetic material as a resource for our health through potential innovations in medicine. It also provides a richer intellectual nutrient for our "biophilia," the "innate [human] tendency to focus on life and lifelike processes" (p. 1). Incidentally, this emphasis on animals as genetic material for human welfare and stimulation is close to an apology for unbridled genetic engineering.

In any case, our concern is with the harm done to a living individual animal that is bereft of species-way. Following Kohak (1984), it would be tempting to argue that an animal's loss of species-way is harmful in terms of the loss of the natural. Kohak speaks of the "moral sense of nature" (p. 70). In addition to the "economy of nature," the efficient working of an ecosystem, "the sense of nature includes also a dimension of value" (p. 70). There is an "integrity, a rightness" to the presence of the chipmunk peering out at us from his or her hideaway. An animal can live in nature in the sense of being sensitive to the rhythms, light, and spatiality of day and night, and of the changing seasons. For Kohak, our contribution to their loss of that sense is a moral issue for there is a rightness in that natural presence for them. The battery chicken or laboratory rat who knows only constant light or temperature is harmed by the deprivation of natural change. By this neo-naturalism, my dog's appreciation of the rhythm of my business day, which is 
hardly synchronized to the temporality of the Maine seasons or days, is a harm. Yet he and I both enjoy that and other socially constructed rhythms. We live together in a mixed community (Callicott, 1988) based on shared and, apparently, enjoyable although unnatural rhythms, boundaries, and other parameters.

Or, following Callicott, we could argue that producing a generic animal is wrong for it is a betrayal of an implicit agreement we entered into with animals of certain species when we first formed mixed communities with them. The guinea fowl turned barnyard chicken did not bargain for this reduction to intensively produced meat and eggs. This is helpful but limited in that it does not indicate in what way the particular betrayal of reduction to generic animal, among the many betrayals of domesticated, laboratory and companion animals, is harmful. It really begs the questions of how and whether the reduction to generic animal is a particular and additional form of harm.

Singer argues that an animal has interests and that he or she is harmed and, therefore, wronged when deprived of situations or objects through which those interests can be realized (1975). However, in these terms, boredom is not merely the absence of such objects. In boredom, an animal has lost the capacity for interest itself, not merely the opportunity to fulfill interests. Beyond the distress inherent to it, boredom is harmful for it deprives an animal, radically, of interest, of that attitude which directs it to the environment as a source of stimulation. In the terms of the present argument, a generic animal is bereft of species-specific interests (and of individual interests as well) for the habitat-habit unity which provides the matrix of those interests has been dissolved. A generic animal is harmed in that, being bored, it no longer has interests.

Incidentally, the addition of this harm may be a problem for Singer's account for is not being an interest-bearer a condition for the application of the pleasure-pain calculus of utilitarianism? Perhaps Singer might argue that even the generic animal was once or is still potentially an interest-bearer and that, therefore, one can estimate the loss of pleasure of unfulfilled interests. However, that claim gets weaker and the estimate more difficult to the degree that an animal is from birth, chronically and permanently a generic animal.

Regan's deontological account appears to work better here. With Regan, we can say that the production of an animal that lives without having interests is wrong, for an animal has an inherent value that inheres in its "having interests." The deprivation of that capacity is a distinguishable form of harm.

We conclude that to cage an animal, in the particular meaning we have given that term, is morally objectionable. Beyond those ontic harms traditionally associated with caging an animal, the pro duction of a generic animal is a distinguishable, additional, and morally objectionable ontological form of harm.

\section{$\underline{\text { Notes }}$}

\footnotetext{
${ }^{1}$ For Heidegger (1962), ontic refers to the particular condition and experience of an entity, that person, dog, or rock; while ontological refers to a more general being, a structure of structures that provide the condition for the possibility of the particular entity to be what he or she or it is.

${ }^{2}$ It is arguable whether this structure is permanently absent or temporarily blocked.

${ }^{3}$ For my general approach to phenomenology, see Shapiro (1985); for a mixed method developed for the study of nonhuman animals, see Shapiro (in press, b.)
}

${ }^{4}$ Arguably, Gallup (1977) has demonstrated a kind of "selfrecognition" in the Great Apes only.

${ }^{5}$ However, Arluke (1988) has found that this objectifying attitude is an ambivalent one.

${ }^{6}$ This reduction to a generic being, readied to disclose itself, is consistent with Heidegger's description of the attitude wherein we live toward objects as "ready-to-hand" as there for and only meaningful in terms of our possible use of that disclosed being (1962, p. 98). However, the present attitude also requires a decontextualizing and ahistorical posture not requisite to Heidegger's zuhanden.

${ }^{7}$ Scarry (1985) describes the moment of the intense pain of systematic torture as an "unmaking" of the world. Systematic torture, then, may be a momentary exception to this distinction between human and nonhuman animals. 


\section{References}

Arluke, A. (1988). Sacrificial Symbolism in Animal Experimentation: Object or Pet? Anthrowoos, 2, 2, 98-118.

Bakan, D. (1971). Disease, Pain and Sacrifice Boston: Beacon.

Barthes, R (1977). The Death of the Author. In S. Heath (Ed.), Image, Music, and Text. New York: Hill and Wang.

Berger, P. \& Luckmann, T. (1966). The Social Construction of Realify. Garden City: Doubleday.

Callicott, J.B. (1988). Animal Liberation and Environmental Ethics: Back Together Again. Between the Species, 4, 3, 163-176.

Devereux, G. (1967). From Anxicty to Method in the Beharioral Sciences. The Hague: Mouton.

Dombrowski, D. (1988). Individuals, Species, Ecosystems: A Hartshornian View. Between the Species, 4, 1, 3-11.

Farber, M. (1968). The Foundation of Phenomenology: Edmund Husserl and the Quest for a Rigorous Science of Philosophy. Albany, State University of New York.

Foucault, M. (1973). The Order of Things: An Archaeology of the Human Sciences. New York: Vintage.

Fox, M.W. (1978). The Dog: Its Domestication and Beharior. New York: Garland.

Gallup, G. (1977). Self-recognition in Primates: A Comparative Approach to the Bidirectional Properties of Consciousness. American Psychologish, 32, $329-338$.

Gould, J. (1982). Panda's Thumb. New York: W.W. Norton.

Gould, J. (1987). Animals and Us. New York Review of Books, 34, $11,20-25$.

Heidegger, M. (1962). Being and Time New York: Harper and Row.

Heidegger, M. (1977). The Question Conceming Technology and Other Essays. New York: Harper Torch.

Herzog, H. (1988). The Moral Status of Mice. American Psychologisi, 43, 6, 473-476.

Kohaks, E. (1984). The Embers and the Stars: A Philosophical Irquiry into the Moral Sense of Nature. Chicago: University of Chicago.

Laing, RD. (1965). The Divided Self. Baltimore: Pelican.

Laing, R.D. \&c Cooper, D. (1971). Reason and Violence: A Decade of Sartre's Philosophy. New York: Vintage.

Lasch, C. (1979). The Culture of Narcissism. New York: Warner.

Lyons, J. (1989, January). Personal communication.

Mason, J. \& Singer, P. (1980). Animal Factories. New York: Crown.

Midgley, M. (1978). Beast and Man: The Roots of Human Nature. Ithaca: Cornell University.
Munson, R (Ed.) (1971). Man and Nature: Philosophical Issues in Biology. New York: Delta.

Polkinghorne, D. (1988). Narrative Knowing and the Human Saences. Albany: State University of New York.

Regan, T. (1983). The Case for Animal Rights. Berkeley: University of California.

Ricoeur, P. (1984). Time and Narrative, trans. by K. McLaughlin and D. Pellauer, 2 volumes. Chicago: University of Chicago.

Scarry, E. (1985). The Body in Pain. New York: Oxford University.

Shapiro, KJ. (in press, a.). Animal Rights v. Humanism: The Charge of Speciesism. Joumal of Humanistic Psychology.

Shapiro, KJ. (in press, b.). Bodily Reflective Modes: A Phenomenological Method for Psychology. Durham: Duke University.

Shapiro, K.J. (in press). Understanding Dogs Through History, Social Construction, and Kinaesthetic Empathy. Anthrozoos.

Singer, P. (1975). Animal Liberation. New York: New York Review.

Singer, P. (1979), Practical Ethics. Cambridge: Cambridge University.

Stone, C. (1974). Should Trees Have Standing? Toward Legal Rights for Natural Objects. Los Altos: William Kaufmann.

Varner, G. (1978). Do Species Have Standing? Environmental Ethics, 9, 1, 57-72.

Wemelsfelder, F. (1984). Animal Boredom: Is a Scientific Study of the Subjective Experiences of Animals Possible? In M.W. Fox \& L.D. Mickley (Eds.), Advances in Animal Welfare Science $1984 / 85$ (pp. 115-155). Washington, D.C.: Humane Society of the United States.

Wilson, E (1984). Biophilia. Cambridge: Harvard University.

\begin{tabular}{||l||}
\hline $\begin{array}{l}\text { Adopt a wild child through Primarity } \\
\text { Primates. By contributing to Jungle Pal } \\
\text { you can help provide some kindness } \\
\text { and respect to the many victims of } \\
\text { hunan torment, abuse, and neglect. } \\
\text { Included among these non-human } \\
\text { animal friends is Willie, a.k.a. Virgil, } \\
\text { the retired Chimpanzee star of the } \\
\text { movie Project X To help, write: } \\
\text { Primarily Primates, Inc., P.O. Box 15306, } \\
\text { San Antonio, Texas 78212-8506. }\end{array}$ \\
\hline
\end{tabular}

